This item was submitted to Loughborough's Research Repository by the author.

Items in Figshare are protected by copyright, with all rights reserved, unless otherwise indicated.

\title{
Partnering with community-an option for infrastructure procurement
}

PLEASE CITE THE PUBLISHED VERSION

PUBLISHER

(C) Thomas Telford Publishing

LICENCE

CC BY-NC-ND 4.0

\section{REPOSITORY RECORD}

Sohail, M., and Andrew N. Baldwin. 2019. "Partnering with Community-an Option for Infrastructure Procurement". figshare. https://hdl.handle.net/2134/3884. 
This item was submitted to Loughborough's Institutional Repository (https://dspace.lboro.ac.uk/) by the author and is made available under the following Creative Commons Licence conditions.

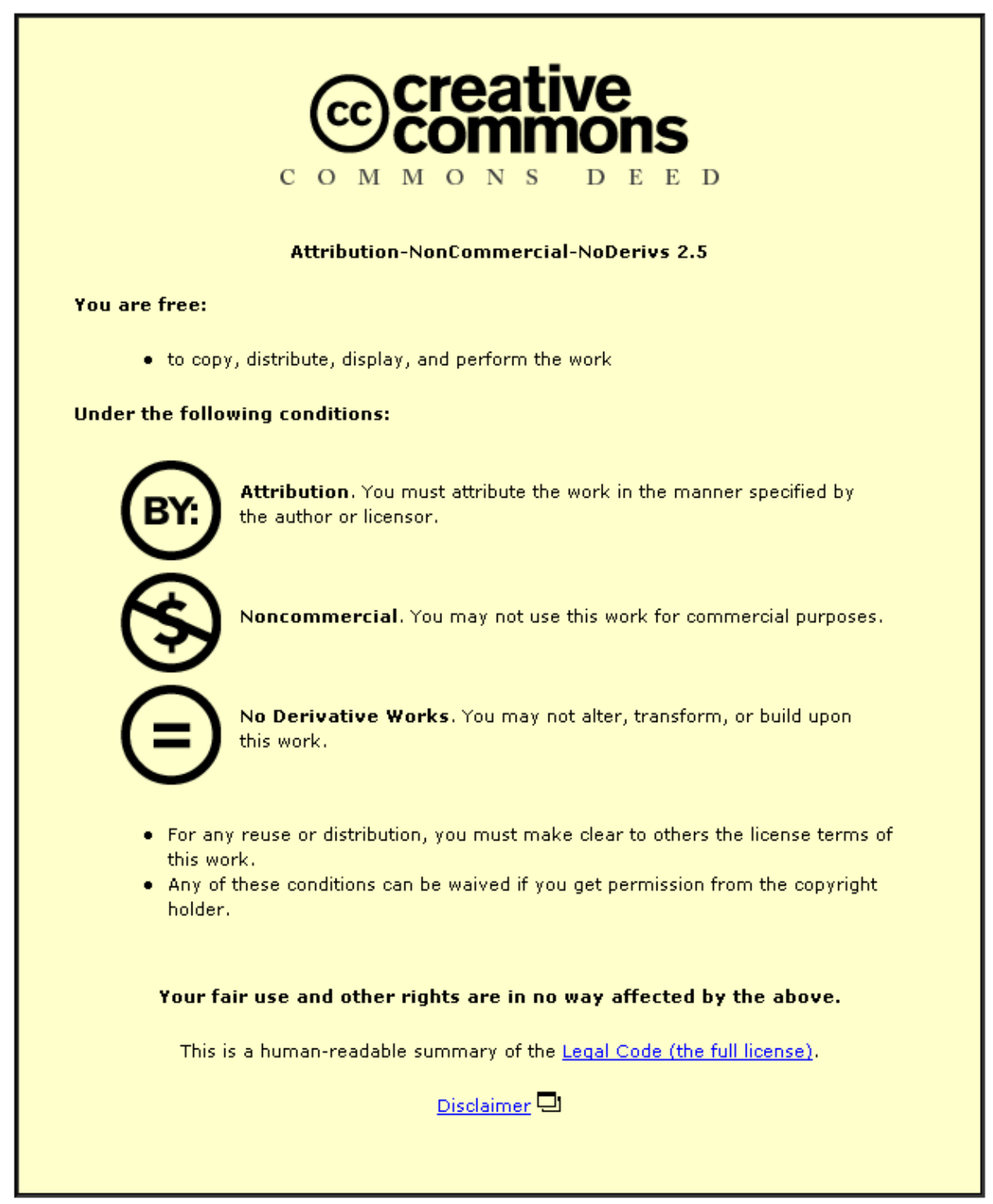

For the full text of this licence, please go to: http://creativecommons.org/licenses/by-nc-nd/2.5/ 

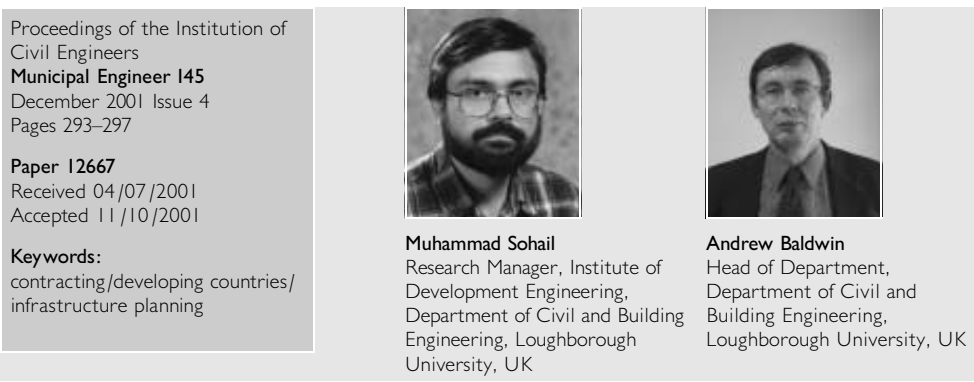

\title{
Partnering with community-an option for infrastructure procurement
}

\author{
M. Sohail and A. Baldwin
}

This paper is about community partnered procurement (CPP) of infrastructure. It looks at a changing role for the community in a general sense, but for householders in settlements in particular. The paper puts CPP in the broad context of different procurement options. It describes the mechanisms, both conventional and unconventional, governmental and non-governmental, that have been adopted to deliver improved urban services in partnership with community. The mechanisms and processes of agreements, procedures and contracts, which are the basis for implementation of infrastructure improvement in low-income communities, are also introduced. The specific focus of the paper is the situation where communities have undertaken the role of the contractor. The paper provides both general experience and case study evidence from Sri Lanka, Pakistan and India. The potential benefits and implications of adopting CPP are described.

\section{INTRODUCTION}

Procurement is the process of buying goods, works or services. There are numerous procurement systems available to the construction client. These may be selected on the basis of the responsibilities of the parties and the risk involved.

The traditional and most common method of procurement is based on competitive tendering. Here the responsibilities for the design and construction aspects of the project rest with different organisations. Clients are attracted to this method on the basis that it will ensure competition, include a transparent decision-making process and show accountability in the spending of public money. Other methods of procurement include integrated procurement systems where design and construction become the responsibility of one organsation, usually a contractor, and management-orientated procurement systems where the emphasis is placed upon the overall management of the design and construction of the project. Here, the construction element is usually carried out by works or package contractors, the management contractor having the status and responsibilities of a consultant. ${ }^{1}$ Other forms of procurement have been developed specifically for detailed administrative/managerial frameworks, for example the British Property Federation System ${ }^{2}$ and the HM Treasury CUP Guidance. ${ }^{3}$ The trend towards private participation in the development of government projects has led to less competitive tendering and more management-orientated contracts that include the provision of finance in exchange for ongoing revenue. These forms of procurement include the Private Finance Initiative (PFI); build, own, operate and transfer (BO0T); and partnering. These methods are described in detail elsewhere. ${ }^{4-7}$ To date, such procurement systems and forms of contract have related primarily to large-scale projects.

New forms of procurement have also emerged for small-scale projects in developing countries. On this type of project the works themselves are minor and usually of low cost, but are nevertheless complex to implement given the physical and social fabric of low-income urban areas. Here the term microcontract is used to refer to the countless number of such contracts whose contract value is typically less than $£ 10000$ and the duration less than one year. Although the accepted best method for ensuring transparency and accountability, the conventional open, competitive tendering procedure is expensive and does not always provide best value. Considering the smallness of scale and complexity, other forms of procurement such as select tendering and negotiated contracts can become more appropriate. Partnering and community partnering implies the need for other than conventional open forms of contract. Such contracts recognise a 'triangle of actors': promoter, engineer and contractor ${ }^{8}$ and their needs. The promoter, having planned and designed the work, wants the best value for money. The contractor wants a good profit. The engineer has the important role of ensuring that the interests of the promoter are met, and that the contractor is duly paid for his efforts. This can involve an enormous range of contentious issues and considerable work in satisfying the various interests in the pursuit of cost, quality and time.

Community groups and individual householders (see Fig. 1 which shows a typical low-income settlement) do not figure anywhere in the procedures mentioned above or the contracts and documentation used in these circumstances. Traditional forms of procurement assume that communities are passive consumers who are deemed to be satisfied if works are undertaken to the satisfaction of the promoter.

Over the past decades there has been a shift in thinking concerning development. Technology- and resource-based theories of the 1960s and 1970s were capital-based blueprints 


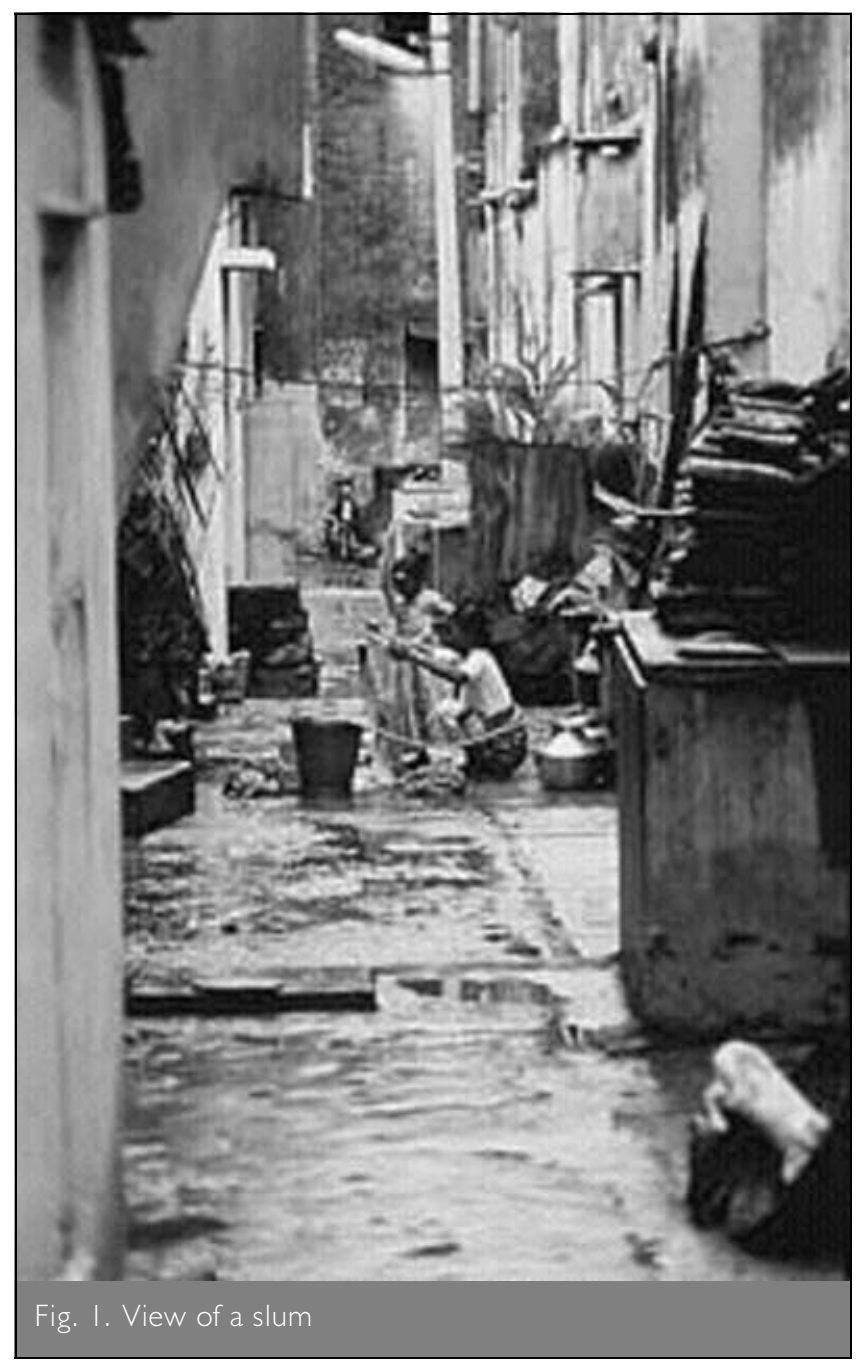

that implied a passive role for beneficiaries, concentrating on transfer of technology and improving government revenue. The new paradigms take a people-orientated approach and more specifically the approach of 'putting the first last'. ${ }^{9}$ Changing values and paradigms have advocated the use of appropriate technology and community participation as a tool in development planning, implementation and management. Accordingly, increasing pressure has been exerted by donors to involve the intended beneficiaries in the planning and implementation of project efforts and in the distribution of the benefits of development. ${ }^{10,11}$

\section{COMMUNITY PARTNERING}

Community partnering may involve the community as the promoter, engineer or contractor. The roles played by a community can be concurrent, that is, the community can play one or more of the three roles in the 'triangle of actors'. Figs 2 and 3 show a process of planning and negotiation. The authors have found examples of each of these forms of involvement.

(a) Community as promoter. The community fully or partially finances the infrastructure at tertiary level. This is restricted to small value contracts, as illustrated by the Orangi Pilot Project works, Sindh Katchi Abadi Authority internal works, Faisalabad Area Upgradation Project and the Clean Settlement Programme Unit (CSPU).

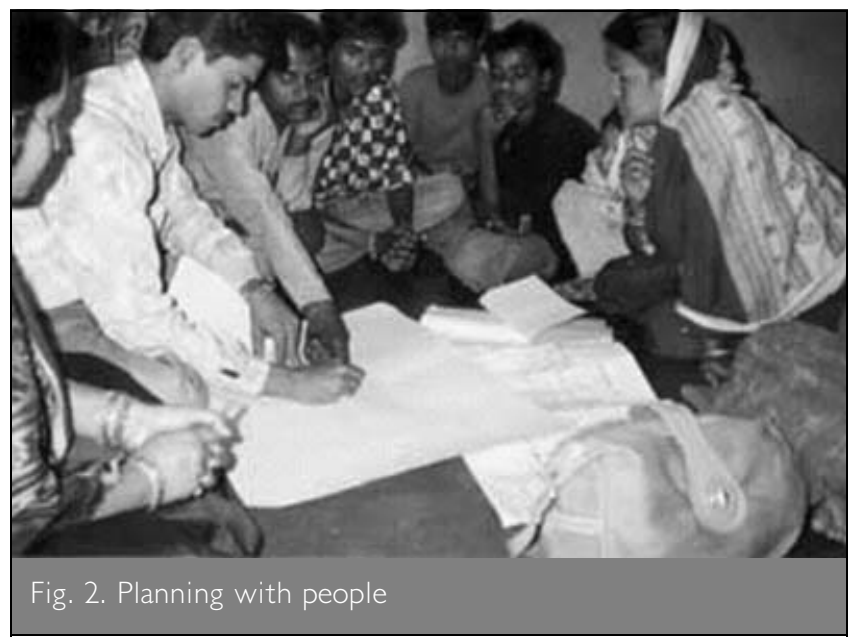

(b) Community as engineer. The community undertakes planning, monitoring and supervision of the contract. Examples are Karachi Metropolitan Corporation/Asian Development Bank, CSPU and Sevanathe.

(c) Community as construction contractor. The community undertakes construction related tasks, partially or fully, for example material purchase, labour works or management. Examples are SKAA internal works; OPP housing and development authority National Housing and Development Authority, (NHDA); and the Slum Improvement Programme, CPSU.

The roles of the community groups within the contractual triangle range from informal (without having a legal contract) advisors to formally appointed micro-contractors with legally binding contracts to construct the works, for which they receive cash payment. Case study evidence indicates that

'urban infrastructure at the local (tertiary) level is not too complicated for ordinary people and local artisans. Urban infrastructure is complex, but nevertheless community groups in different situations demonstrate their ability to play a positive role. They are neither well-equipped with construction plant nor are they large organizations. ${ }^{12}$

See Fig. 4 showing surveying work in progress.

Community partnering embraces a variety of roles and responsibilities in a relationship or contract. It is an approach

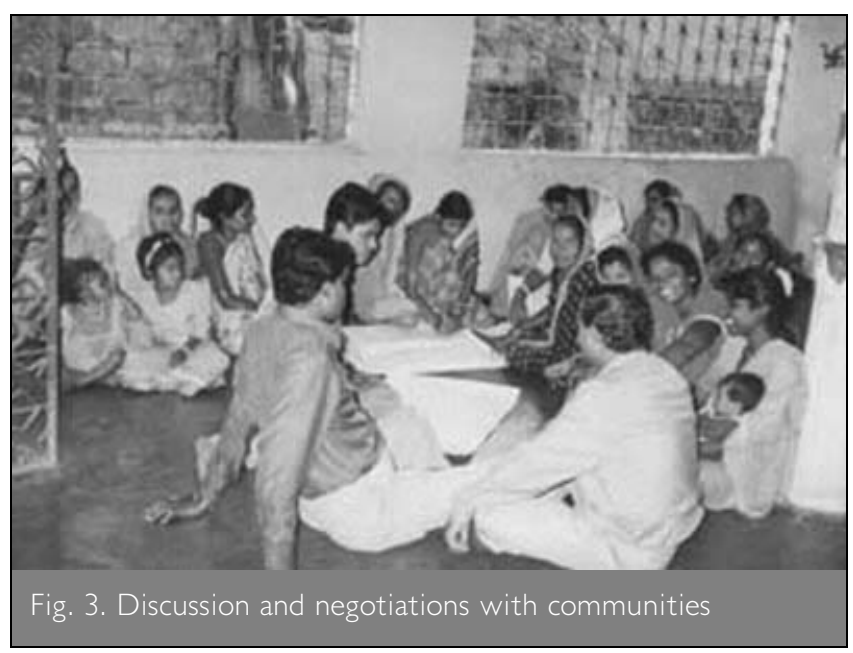




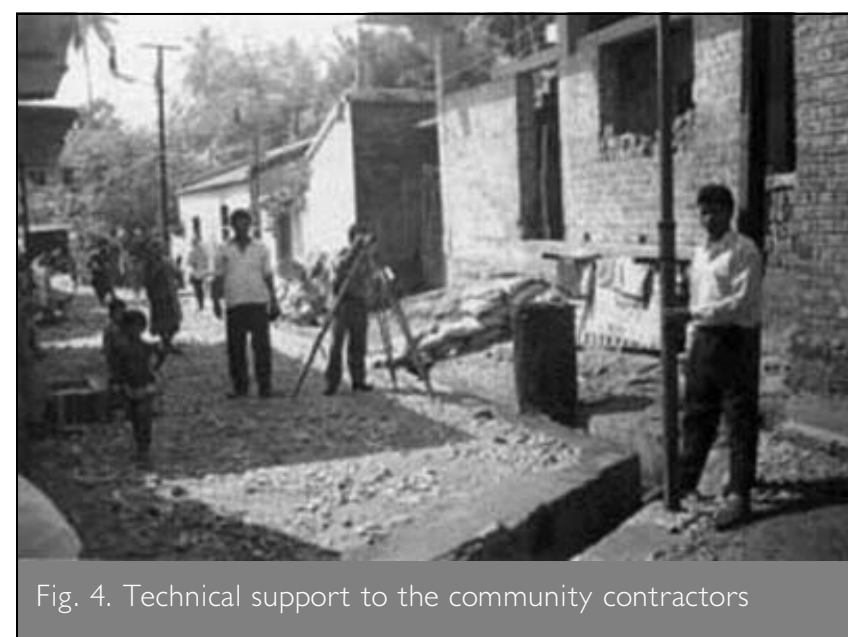

that emphasises a relationship between the stakeholders that is non-adversarial for achieving mutually agreed objectives. In its broadest sense, it reflects both the continued involvement of people with the planning, implementation and the sustenance of local infrastructure and service improvements, and with income generation, enterprise development and skills training. A key aspect in community-participated procurement is the achievement of 'goal alignment', thus producing the efficient contracts of promoter and contractor. The main benefits of this approach are as follows.

(a) There are additional benefits which stem from the procurement of infrastructure through community partnering. These include benefits to the local micro-economy, enterprise development, and income generation for lowincome groups. In community partnering, community members are directly affected by the way in which work is carried out and have a strong incentive to see that it is completed properly. This includes improved quality of work through involvement in planning, decision-making and the creation of a sense of ownership and interest in maintenance.

(b) Resources can be channelled into the community rather than being siphoned off by outside contractors. Whereas conventional procurement of infrastructure has a single benefit, namely the provision of the infrastructure itself, community partnering can double the benefits obtained from investment. Infrastructure is provided and employment opportunities and enterprises are created in the community.

(c) People are empowered to take more control of their own lives. Capacity building and development of skills of micro-contractors and community groups, together with the formation of local societies to carry out the work, contribute to this aim.

(d) There is a stronger sense of community and belonging for community members.

(e) Increased access to local knowledge is gained on issues such as the location of existing services.

( $f$ ) There is a reduction in the potential for disputes with community members in the course of work on site.

Community partnered procurement implies a number of changes. (a) Full acceptance of the urban poor as primary stakeholders in local infrastructure provision.

(b) Developing longer-term more open-ended relationships, encompassing joint financing, planning, design, implementation, hand-over and maintenance.

(c) Promoting cooperation both formally and informally with government agencies and non-governmental organisations (NGOs).

(d) Wider targeting of the urban poor, rather than solely areabased dwellers in specific slums, as local inhabitants do not necessarily carry out improvement works themselves because of lack of time and relevant skills.

(e) The procurement set-up, including standard forms of contract, should explicitly recognise the role of community as end-users.

All of these forms of involvement produced related but differing results. Within the scope of this paper we shall focus on the community as construction contractor.

\section{THE COMMUNITY AS CONSTRUCTION CONTRACTOR}

A community contract is a contract between a community and another partner (that could be public sector, private sector or donors etc.) to undertake tasks to improve or contribute to improvement in the living conditions of the community. Since community contracting is relatively new, there are no standards for community contracts. Conventional conditions of contract are designed to use professional contractors and as such are restrictive for community. 12 'Community contracting can be defined as the contracting out of the construction component of infrastructure procurement to a community. ${ }^{13,14}$ 'This would include maintaining of financial records, purchasing of materials, hiring of labour and actual construction. ${ }^{, 15}$

In engineering terms, the works involved in such contracts are minor and usually of low cost. Nevertheless, these are often complex to implement given the physical and social fabric of low-income urban communities. The process of explaining the concepts, assessing the capacity of the community groups, entering into negotiations and providing technical support during construction are all resource-consuming activities. In addition there are also costs for the communities: 'Community groups invest a lot of their resources including time during the development of the participation process, and in gaining sufficient confidence to become involved in infrastructure procurement. $^{10}$

'The delivery of basic services such as water supply, roads, drains in low income settlements through self help is not yet a generally accepted principle, despite experiments in various cities. ${ }^{16}$ The lead in contracting out to communities was taken in the late 1980 s by the NHDA of Sri Lanka. The communities undertook the role of the contractor; they call it the 'community contracting system'.

The three core principles of the community construction contract system are as follows.

(a) The delegation of the responsibility for the provision of infrastructure in low-income settlements from the government to the end-users of the infrastructure. 
(b) The development of a sense of responsibility among the end-users for the maintenance and management of that infrastructure as a result of their involvement in its provision.

(c) The commitment of the government to provide all technical support, training and information required by the end-users to carry out these responsibilities. ${ }^{17}$

\section{BENEFITS FROM COMMUNITY CONTRACTING}

The benefits of community contracting are the lower costs of construction for the government, the creation of employment in the low-income settlement, on-the-job training in technical and managerial skills, a higher quality of work than that achieved by commercial contractors, speedier completion of works, greater satisfaction by the users and an enhanced feeling of responsibility by the community for the amenity provided. ${ }^{14}$ Community contracts are awarded faster than normal contracts because there is no call for tenders and the community can save money by using free community labour. In $31 \cdot 1 \%$ of cases the Community Development Council hired labour to do the construction work. In $38 \cdot 1 \%$ of cases the community did all the work itself. 'Masons and tradespeople who have been involved in a community construction project confirmed that they learnt new skills, such as grading, levelling and the use of the metric system from the technical officers of the NHDA. ${ }^{, 17}$ Other benefits included self-confidence and ability to deal with officials and formal financial institutions. However, the community contract system did not result in the speedier completion of work, $49 \cdot 2 \%$ of contracts experiencing a time over-run. ${ }^{17}$

\section{FACTORS WHICH CONTRIBUTE TO THE SUCCESS OF THE PROJECTS}

The case studies in References 13 and 14 have highlighted a number of issues relevant to a discussion of community partnering. These are now discussed in turn.

\section{I. Site engineers}

The site engineers provide strong technical support to the community contractors especially in extracting relevant information from technical designs and specifications to enable the execution of the works. However there is a fine line between assisting the community and creating dependency. There is a need therefore to build on capacity in understanding contract documentation, conditions, drawings, bills of quantities and specifications. The communities may then go on to develop community-based specifications, standard designs and simple drawings. Standardising details makes it more convenient for the community to estimate and construct infrastructure.

\subsection{Standard community contracts}

There is a need for standard community contracts that stipulate

(a) the size of the contract

(b) how infrastructure work should be described in documents

(c) appropriate wage levels and work norms

(d) procedures to elect and rotate labourers

(e) profit levels

(f) risk

(g) accident insurance

(h) tools, equipment and protective gear

(i) payment.

\subsection{Defining the community contract}

As the community contract should be understandable for the community, the contract needs to be kept as simple and practical as possible, with clear responsibilities, clearly defined roles, training needs and reporting procedures. For Hanna Nassif, "community contracts are in the range of up to $5 \cdot 3$ million Tsh (£4400). The community feels confident to handle work up to Tsh 1 million (£833) independently. ${ }^{9}$ Although the quality of work is acceptable, there are significant time and cost over-runs in some of the community contracts undertaken. The increase or decrease in the size of the contract should relate to the capacity and performance of the contractors. Once the time and cost performance are under control the gradual increase in both the capacity of the community and the contract scope can begin.

\subsection{Wage levels}

Wage levels may include the minimum national level, market rate in urban areas, wages paid by urban authorities, wages earned by workers on a private contractor job and community members paid for work in their own community. Lower wages may reflect the benefits workers gain from the assets created, the amount of training and skills upgrading needed and the need to discourage workers from outside the community from participating in the project. Worker rotation has been established and this gives access to all the interested workers. A lottery system is used to give everyone a fair chance to work. The selection system should be transparent and agreed upon by the community. It may also be decided to reserve a proportion of the workforce for disadvantaged groups. Superior performance should be encouraged by the award of commendation certificates. The dangers of exploiting 'voluntary' labour on cost grounds or ignoring the opportunity cost of voluntary labour must be fully considered.

\subsection{Reporting and information systems}

Reporting and information systems should be designed to cater for the requirements of all the stakeholders: between CBOs and the community; between site and government; between the project and the wider professional institutions. Systems should be in place for

(a) accident reporting

(b) documenting quality issues

(c) site instructions

(d) office procedures

(e) performance monitoring

(f) documentation of the process

(g) project procedures (contracts, O\&tM, safety, quality control and community participation).

\subsection{Financial accounting}

Members of the community need to be trained to handle financial accounts. There needs to be separate financial accounts for

(a) each community contract

(b) O\&tM

(c) overheads, management fees and surpluses

(d) regular auditing

(e) sharing the summary of financial information with the community. 
Above all it should be remembered that the communitypartnered procurement is only a means to the wider objective of community development. The processes are more important than the product. There need to be realistic assumptions made about the capacities of the project partners. There is also a need to make judgements about the willingness of partners in applying their capacities. Involving the community groups in infrastructure works changes the existing power relations among the partners: 'Professional support to non professional entities like the community requires special skills, attitudes and temperament. $^{18}$

At the end of the project the teams do not have to disband. Community-based organisations may register as private contractors and develop enterprises; they may expand their approach to solve other problems; and they may continue to work within the community.

\section{SUMMARY}

Community partnering on micro-projects between the urban public sector and suitable urban communities is an appropriate procurement strategy that has been used successfully in the procurement of tertiary-level infrastructure for urban poor communities in the developing countries. Communities involved in the micro-contracts studied have demonstrated their capacity to participate in and work with government bodies in the procurement of infrastructure. They are capable of taking on a wide range of roles and responsibilities, which correspond to those of client, engineer and contractor in routine procurement. This requires new skills, both technical skills and also negotiation and influencing skills.

In cases where the community acts as promoter and/or engineer, the community needs to be supported technically by either an NGO or the officials of the urban government. The requirement on the part of urban government is to encourage what is happening at the grass roots level and support the community in improving its performance. Changes in the regulatory framework, or alternatively not exercising the controls of the current framework, are implied if this process is to be developed. Again, new skills and attitudes are needed by government/NGO staff.

Community contracting is an example of a practical response to failure in traditional delivery mechanisms and the need for innovative change. Innovation in the procurement process is required if the community acts as the contractor but this may well be possible from within existing government procedures that allow for alternative procurement strategies. (The government of Sri Lanka has sustained innovations for over ten years and has started to assimilate them in its rules and procedures.)

There is no single identifiable role model for participation in urban infrastructure procurement. Community contracting and partnering in procurement generally performs well in terms of the conventional contract performance objectives of time, cost and quality. The performance is comparable in terms of time and costs with infrastructure procured through the routine tender contract process. There is also evidence that the quality of the infrastructure procured through community partnering is superior as compared to that procured through the routine tender contract process. The poor deserve a quality, functioning infrastructure and community partnering offers a new way to procure it.

\section{REFERENCES}

1. Masterman J. W. E. An Introduction to Building Procurement Systems. E \& FN Spon, London 1992.

2. British Property Federation. Manual of BPF System: the British Property Federation System for Building Design and Construction. BPF, 1983.

3. HM TREASURY. CUP Guidance No. 36: Contract Strategy Selection for Major Projects. HMSO, London, 1992.

4. TAM C. M. Build-operate-transfer model for infrastructure development in Asia: reasons for successes and failures. International Journal of Project Management, 1999, 17, No. 6, 377-382.

5. GrubB S. R. T. Private finance initiatives-public private partnerships. Proceedings of the Institution of Civil Engineers, 1998, 126, 133-140.

6. Tiffin M. and Hall P. PFI-the last chance saloon. Proceedings of the Institution of Civil Engineers, 1998, 126, 12-18.

7. Pena-Mora, Feiniosky and Harpoth, N. Effective partnering in innovative procured multicultural projects. Journal of Management in Engineering, 2001, 7, No. 1, 2-13.

8. AtKinson A. V. Civil Engineering Contract Administration. Stanley Thorne Ltd, 1992, 2nd edn.

9. ChAmbers R. Rural Development: Putting the Last First. Longman, 1983.

10. CoHEN and Uphoff. Participation's place in rural development: seeking clarity through specificity. World Development, 1980, 8, 218-235.

11. KeNT and Rimarachin. Rural public works construction in the Andes of northern Peru; the role of community participation. TWPR, 1994, 16, No. 4, 357-372.

12. SoHAIL M. An Investigation into the Procurement of Urban Infrastructure in Developing Countries, $\mathrm{PhD}$ thesis, Loughborough University, 1997.

13. CоттоN A. P. and Sohall M. Community partnered procurement-a socially sensitive option. Waterlines, 1997, 16, No. 2, 24-26.

14. CotTon A. P., SohaIl M. and TAYLeR W. K. Community Initiatives in Urban Infrastructure. WEDC, Loughborough University, 1998.

15. MeEKIngs H. Community Involvement in Infrastructure Procurement; a Case Study Report Based on Experiences from Vijaywada, Cuttack and Cochin, India. DFID Urban Poverty Office, India, 1997.

16. PathiRAna and Sheng. The community contract system in Sri Lanka; an innovative approach for the delivery of basic services to the urban poor. Habitat International, 1992, 16, No. 4, 3-14.

17. Habitat. The Community Construction Contract System in Sri Lanka. United Nations Center for Human Settlements, Nairobi, 1994.

18. ILO/Sohail Khan K. M. Community Partnered ProcurementCommunity Contracting. Hanna Nassif Urban Infrastructure Project, Dar Es Salaam, Tanzania, 1998. 